\title{
Creating an online art exhibition: The impact of online context on the Internet user's experience and behaviour
}

\author{
Urszula Świerczyńska-Kaczor \\ The Jan Kochanowski University \\ ul. Żeromskiego 15, 25-369 \\ Kielce, Poland \\ Email: swierczynska@ujk.edu.pl
}

\begin{abstract}
The paper aims to contribute to the discussion about the implementation of virtual art galleries on the websites of art museums and individual artists. This paper focuses on the analysis of the impact of online context on the Internet user's experience and the user's recommendation of the website. The research problem was discussed with reference to the results of an empirical study. The present empirical study led to the following conclusions: 1 . the confirmation of the hypothesis about the positive impact of enhanced context on the respondent's perception of the art presentation; 2 . the rejection of the hypothesis about the positive impact of enhanced context on the viewer's recommendation of the virtual gallery; 3 . the rejection of the hypothesis about the mediating role of interest in art on the viewer's preferred context of virtual art gallery.
\end{abstract}

\section{INTRODUCTION}

$\mathrm{N}$ OWADAYS many museums integrate the online presentation of digitalized art images within their website, offering Internet users the opportunity to visit and search through online virtual art galleries. The online art galleries are also an essential feature of the websites of many individual artists who 'exist' and present their work mostly, or exclusively, online. So far, there are few research studies which compare the art experience in the traditional museum with the online art experience. However, some studies suggest that virtual art galleries may be perceived as unsatisfactory: the artworks in the museum environment were found to be more arousing, positive, interesting and liked, and also better remembered, by viewers compared to the computer presentation (Brieber, Nadal and Leder 2015) and the online visit was perceived as less pleasurable and more passive than the actual visit to a traditional museum (Jarrier \& Bourgeon-Renault 2012). Therefore, on one hand there is an obvious need for developing online art galleries for promotional, informational and educational purposes, on the other hand - it seems that the existing online artworks exhibitions do not fully meet the needs of potential viewers.

This paper focuses on the analysis of the impact of online context which influences the Internet user's experience with the online exhibition and user's intention to recommend the website of art gallery. The paper points to the results of an empirical study based on the implementation of microfictions as a context for the online art exhibition.

The paper is organized as follows: in the next section, the research problem was discussed with reference to a literature review. This part of the article explicitly illustrates that the research problem should be approached from different angles, and the research needs to be based on the integrated framework built within (at least) the psychology of art, the neuroaesthetics and managerial studies. The following section presents the procedure of the empirical study, which aimed to 'capture' the connection between the enhanced context of the virtual art gallery and the attitude and behaviour of the respondent. For the purposes of empirical study the virtual art gallery with two options of art presentation (artworks with standard information and the artworks with microfictions) was developed. The article ends with a discussion summarizing the empirical results, and indicating the managerial implications and future research.

\section{The Problem}

The art museum/gallery website creates the online context of artworks presentation and therefore frames the artwork in a way which influences the perception of the viewer. For online art galleries the content of art presentation usually includes metadata about the artwork such as: name of the artist, the medium, creation date and the size of the artwork. What if the virtual art gallery embeds more than 'standard' information e.g. music which accompanies the viewing of particular fine art work, a poem or other form of artistic expression? Does it lead to positively enhancing the Internet user's experience? Does this 'mixture' of art objects from different artists - musicians, painters, graphic artists, poets or writers - create positive synergy in the process of customer experience? It is not unusual to enhance the customers' experience by employing multimedia (e.g. sound, music, additional art-works such as photographs or even theatrical performance) in order to enrich the customer's experience during the visit to the physical art museum or gallery. 
However, the websites of traditional galleries do not usually incorporate such extraneous elements to enhance virtual tours.

The present study focuses on analysing the impact of the context, which includes microfictions as the 'enhanced frame' for online art galleries. Microfictions (or flash fiction, sudden fiction, minute stories, short-shots) are a contemporary miniature narrative genre of literature, which are (usually) shorter than 700 words (Nelles 2012). Therefore, the main research problem is stated: to what extent does the enhanced context of art galleries impact on the online viewer's experience and behaviour? To investigate this connection, at least three different constructs should be taken into account:

1. The design of the website with the online art exhibition, including graphical and multimedia elements.

2. The outcomes of the viewer's experience:

a. Outcomes connected with art appreciation;

b. Outcomes connected with the viewer's perception of gallery/museum brand;

3. Viewer characteristics e.g. interest in art, gender, age, motivation to visit a virtual art gallery/museum

\section{A. Outcomes of experiencing the online art}

In the literature, the models aiming to explain the viewer's art experience varied as the researchers implemented different frameworks in their analyses. For example, the model first proposed by Leder, Belke, Oeberst \& Augustin in 2004, and then further discussed in the paper of Leder \& Nadal (2014) provides the integrated framework of the process of understanding the aesthetic appreciation of art, and points to aesthetic judgment and aesthetic emotion as the different outcomes of art experience (Leder \& Nadal 2014). The model proposed by Pelowski \& Akiba (2011) emphasizes the transformative impact of art, the initial disruption, the subsequent meta-cognitive reflection and conceptual change. A relatively new stream of literature, based on the implementation of neuroimaging techniques (e.g. functional magnetic resonance imaging (fMRI), electroencephalography (EEG), magnetoencephalography (MEG)), seeks for the explanation of art experience at the neurological level: showing the way in which particular art stimuli activates the human brain (see the interesting research presented by CelaConde, Agnati, Huston, Mora, \& Nadal 2011).

A review of studies from literature indicates that the researchers include and measure different constructs within the 'general dimension' of viewer's art experience, as for example:

- the construct of aesthetic appreciation, the construct of appraised ability to understand the paintings (Swami 2013);

- the dimensions of liking, the interest and emotional valence (Gartus and Leder 2014);

- the dimension of liking, interest, understanding and ambiguity (Brieber, Nadal, Leder, Rosenberg 2014)
The stream of literature of the psychology of art or neuroaesthetic does not focus on the relation between the viewer's art experience (on traditional or online market) and the impact of this experience on the perception of the art gallery brand which displays the artwork (although the problem - how the image of the gallery influences the viewer's perception of artwork was investigated e.g. Kirk, Skov, Hulme, Christensen, \& Zeki (2009)). Within the scope of under-researched topics there are (at least) the following connections:

- the online art experience and the patron's attitude to the brand (e.g. perception that the brand of a particular artist is trustworthy);

- the connection between the online art experience of the viewer and the viewer's behaviour connected with the possible purchase e.g. intention to buy the ticket or artwork;

- the online viewer's intention to recommend the art gallery brand as a result of visiting the art online gallery;

The above mentioned business outcomes as the result of the patron's visit to a virtual gallery are linked with broader constructs such as the art gallery brand equity and the customer equity. So far, there are few research papers in this field of study, and many issues need further investigation, including fundamental questions about the elements which constitute the brand equity of a virtual art exhibition, and about the drivers of customer equity for the website with a virtual art exhibition.

With regards to the traditional market, Camarero, Garrido, \& Vicente (2010) indicate the loyalty, perceived quality, brand image and brand values as the factors influencing the brand equity for art exhibitions. However, it seems possible that the patrons may perceive the website and the traditional brand of art museum/gallery differently. For example, on the basis of direct visits and seeing a particular exhibition, the patron perceives the brand of the art museum negatively (offering too few exhibition items, low quality of organizing the service etc.), however the website with a virtual art gallery of the same art museum is perceived as very well-organized and well-developed. This example illustrates that the viewer's perception of virtual gallery brand and the 'traditional' art gallery brand may be partly independent constructs, and the relation between these constructs may be mediated by other factors, for example the viewer's previous experience.

In the present empirical study the viewer assessed the virtual gallery - with or without the microfictions- in the following dimensions:

- the dimensions connected with art experience such as of 'liking the presentation' and 'the richer experience'

- the dimension connected with the business outcome - 'the intention to recommend the virtual gallery'. 


\section{B. The context of online art presentation}

Contrary to the formalist views of art, nowadays the context in which the artwork is viewed has been recognized as a significant factor influencing the viewer's experience with art. Its impact on art perception are well-illustrated by, for example the Duchamp's 'readymade' artworks ( 'Bottle Rack', 'Fountain', 'Bicycle Wheel') or the Pop Art movement (see e.g. discussion in Leder \& Nadal 2014, Gartus \& Leder 2014).

The context in which artwork is presented has been investigated and discussed in the literature, indicating the impact of different contextual aspects on the viewer's experience. The study of Leder, Carbon, Ripsas (2006) pointed to the role of elaborative and descriptive titles of abstract and representative paintings. Swami (2013) examined the effects of different types of information (elaborate, content specific information, broad genre information, titular information, no contextualizing information) and different art styles (abstract artworks, representational paintings) on understanding and aesthetic appreciation. Kirk, Skov, Hulme, Christensen, \& Zeki (2009), using the neuroimaging technique, investigated the perception of the image labelled either as an artwork belonging to the art gallery or an image generated by a computer. In another study with usage of fMRI, Cupchik, Vartanian, Crawley, \& Mikulis (2009) investigated the differences in perception of art images under the pragmatic and aesthetic conditions.

Despite the difference between the presentation of an art object in a physical museum and the laboratory environment, most of the studies with reference to art experience were conducted within laboratory settings. Therefore, it seems plausible, that the results obtained in the laboratory settings may be relevant to the discussion about the creation of online art exhibitions.

In the online environment, the context of presentation is created not only by information about the art, but also by the scope of the elements constituting 'the design' of the website. The following elements of a museum website may influence the perception of the Internet user: 1. Content, 2. PresentationMedia-Format-Appearance, 3. Usability, 4. Interactivity \& Feedback, 5. E-Services, 6. Technical (see the framework for evaluating the museums' websites developed by Pallas and Economides 2008). Among these elements, the option of creating personal digital collections is particularly important as it serves: for example, to facilitate the visit in the museum in person or to facilitate learning (Marty 2011).

The important distinction between the museum websites lies in the format presentation based on 2D websites versus the 3D virtual environment. Nowadays the object of art may be $3 \mathrm{D}$ digitalized by the implementation of different techniques (for example laser scanning techniques; shape from structured light, from silhouette, from video, from shading, and shape from texture - Pavlidis, Koutsoudis, Arnaoutoglou, Tsioukas, \& Chamzas 2007), and the Augmented Representation of Cultural Objects (ARCO) system allows the creation of virtual 3D museum exhibitions (Sylaiou, Mania, Karoulis \& White 2010). Some individual artists use the 3D virtual world's environment, such as Second Life, to create a virtual gallery which allows the viewer to be immersed in the space. In the case of fine art most digitalized exhibitions are based on the traditional 2D presentation on the website. The present empirical study also focuses on the 2D presentation format, and the context created by the implementation of additional element - microfiction.

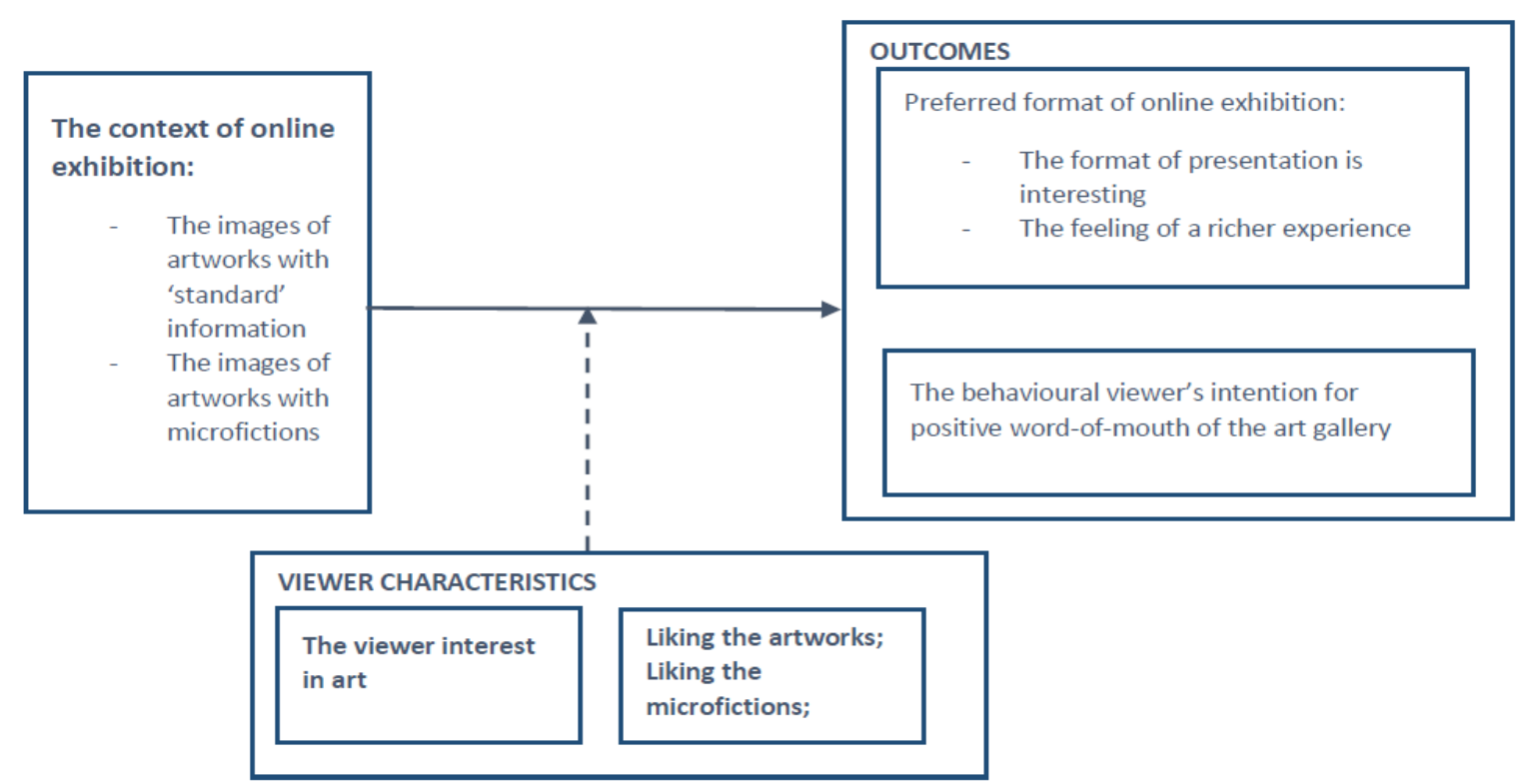

Fig. 1 The framework for empirical study 


\section{The viewer characteristics}

The one of the crucial factors connected with viewer characteristics is the viewer's motivation. The museum websites aim to fulfil the different Internet user's informational needs: obtaining information relevant to the process of planning the visit to the physical museum, selfmotivated research for specific content information, looking for the information connected with assigned research or being engaged in casual browsing (Skov \& Ingwesen 2014). In the case of the individual artist (painter, graphic artist, photographer) while the website often serves as the sales channel, the motivation of potential customers may also be connected with a purchase.

The viewer's characteristics which may have an impact of the viewer's art experience are, for example aesthetic fluency (Swami 2013), current affective state and specific art interest (Gartus, Leder 2014), and expertise in art (Leder, Nadal 2014). In the case of online galleries the spectrum of factors should be widened to incorporate aspects related with Internet and computer usage. For example, Corredor's (2006) study with reference to museum websites points out that the general previous knowledge (in the field corresponding with museum) influences the goal setting process and the usage of the content of the website. For the virtual gallery the viewer's 'general' level of computer literacy may be an important factor, especially in the situation where the lack of computer skills may hamper the viewer's experience.

\section{THE EMPIRICAL STUDY: HYPOTHESES, THE PROCEDURE AND THE RESULTS}

\section{A. Hypotheses}

The present study aims to investigate the connections between the context of presentation - the artworks with or without the microfictions - and the following outcomes (Fig. 1):

- the viewer's perception of the virtual gallery with particular context as an interesting way of presentation;

- the viewer's feeling of 'rich' experience connected with viewing artwork in the particular context;

- the viewer's intention to recommend the virtual art gallery to a friend;
The other factors included in the present study are: the interest in art, and the level of liking the artworks and microfictions.

In the present study, the following hypotheses were tested:

H1: The online enhanced context with microfiction leads to a more positive attitude of the respondent towards the website in the dimensions of liking the website and offering a 'richer' experience.

$\mathrm{H} 2$ : The online enhanced context with microfiction leads to the behavioural intention of the viewer: the intention to recommend the website to a friend

H3: The viewer's interest in art is a factor which influences the preference of the virtual gallery by the viewer.

\section{B. Participants}

The study was conducted in Poland, in January 2015, among 50 young respondents ( 32 women and 18 men), age 20-35 (the group of respondents was homogenous as to the age factor). The respondents were management students, without formal background knowledge of art.

\section{The procedure}

The website of a virtual galley was developed for the purpose of the present study. In the introduction to the study the respondent was informed that the website was a part of a future virtual tour being developed by a new online art gallery. On the introductory page the respondent was asked to visit the next two pages, titled 'Virtual Gallery' and 'Virtual Gallery with Microfictions', and then to fill in the online questionnaire. Five artworks of a local artist were selected and the images were presented on the website. On the page 'Virtual Gallery' the images of artworks had a 'standard' description: the artistic pseudonym of the author of the artwork, the title of artwork, the medium of which the artwork was created and the size of the original work (length and height in centimetres). The technique of the artworks varied: acrylic on canvas (one artwork), pastels (two artworks) and graphics (two artworks). On the page titled 'Virtual Gallery with Microfiction' each image of artwork was accompanied by a short microfiction. The topic of each microfiction aligned with the main concept of the artwork. The length of the microfictions was between 22 and 84 words, the name of the

TABLE I.

THE RESPONDENTS' PREFERENCES FOR THE CONTEXT OF ARTWORKS PRESENTATION; STATISTICALLY SIGNIFICANT DIFFERENCE MARKED *

\begin{tabular}{|c|c|c|c|c|c|c|}
\hline & \multicolumn{3}{|c|}{ All respondents $\mathrm{N}=\mathbf{5 0}$} & \multicolumn{3}{|c|}{$\begin{array}{l}\text { The group of respondents - similar liking of } \\
\text { artworks and microfiction } n=44\end{array}$} \\
\hline & $\begin{array}{c}\text { standard } \\
\text { presentation }\end{array}$ & $\begin{array}{l}\text { artworks with } \\
\text { microfictions }\end{array}$ & $\begin{array}{l}\text { I don't } \\
\text { know }\end{array}$ & $\begin{array}{c}\text { standard } \\
\text { presentation }\end{array}$ & $\begin{array}{l}\text { artworks with } \\
\text { microfictions }\end{array}$ & $\begin{array}{l}\text { I don't } \\
\text { know }\end{array}$ \\
\hline $\begin{array}{l}\text { The more interesting presentation of } \\
\text { artworks is on the website with... }\end{array}$ & $20 \% *$ & $70 \% *$ & $20 \%$ & $16 \%$ & $73 \%$ & $11 \%$ \\
\hline $\begin{array}{l}\text { My experience connected with visiting } \\
\text { virtual art gallery was richer while I visit } \\
\text { the website with ... }\end{array}$ & $24 \% *$ & $64 \% *$ & $24 \%$ & $18 \%$ & $68 \%$ & $14 \%$ \\
\hline $\begin{array}{l}\text { I would be more likely to recommend the } \\
\text { visit to the museum website to my friends } \\
\text { if the museum website included the } \\
\text { artwork presentations as at the page of the } \\
\text { website with ... }\end{array}$ & $24 \%$ & $54 \%$ & $24 \%$ & $20 \%$ & $55 \%$ & $25 \%$ \\
\hline
\end{tabular}


author of each microfiction was clearly indicated on the website.

The procedure of the study was followed as:

a) First step: the respondents were introduced to the concept of the study.

b) Second step: The respondent saw the page 'Virtual Gallery'

c) Third step: The respondent saw the page 'Virtual Gallery with Microfiction'

d) Fourth step: Respondent filled in the questionnaire. The online questionnaire was divided into three groups of questions.

- $\quad$ First group of questions were directly related to the virtual gallery.

- In the second group of questions, respondents were asked to visit the digital exhibitions of the National Museum in Warsaw. After visiting the website, the respondents filled in the part of the questionnaire which refers to the respondents' attitude to the process of creating virtual galleries by museums.

- The third group of questions refers to the profile of respondents. Apart from gathering data about their gender and age, the questions refer to their interest in 'general' art and their interest in visual art.

\section{Results}

As the respondent's attitude to the art presentation may be influenced by liking the artworks or microfictions themselves, the respondent was asked to rank the level on which she or he generally likes the artworks or microfiction: as the general feeling about 'liking the microfiction' or 'liking the artworks'. There was no significant difference in respondents' feeling of liking of artwork and the microfictions: about half of the respondents $(46 \%)$ liked the presented artworks and a similar percentage of respondents $(50 \%)$ liked the microfictions. The averages of 'liking' were 3.34 and 3.42 for the artworks and for the microfictions respectively.

The majority of respondents $-88 \%$ - ranked their liking for the artworks and microfictions similarly - the difference between 'liking' wasn't greater than one point in the scale of 1 to 5 points. The group of 6 respondents ( $12 \%$ of the sample) preferred one of the presented forms: the difference between the 'liking' was greater than 1 point.

The interest in art and in visual art varied among the respondents:

- The $38 \%$ of respondents declared that they are not interested in art, with reference to the visual art also it was the group of $38 \%$ respondents

- The $26 \%$ of respondents declared their interest in art, with reference to visual art $-30 \%$

- The group of respondents rated their interest as 'neutral' ( 3 points on the $1-5$ points scale) in art was $-36 \%$, in visual art $-32 \%$

The study led to the following results (see Table I, Table II, and Table III):

1. The respondents perceived the artwork presentation with microfictions as much more interesting than the 'standard' presentation. The webpage with microfiction was selected as favourable in this dimension by $70 \%$ of respondents compared to the $20 \%$ of the respondents preferring the 'standard presentation' (the statistically significant difference $\mathrm{p}<0.05)$.

2. $64 \%$ of respondents stated that the virtual gallery with microfiction 'offers a richer experience' compared to the $24 \%$ of respondents who preferred the 'standard' presentation (the difference is statistically significant $\mathrm{p}<0.05$ )

3 . If the museum website included artworks and microfiction, the $54 \%$ of respondents would recommend their friends to visit this museum website, compared to the group of $24 \%$ who would recommend the website with the standard presentation (no statistically significant difference)

4. Relations between the variables 'more interesting presentation', 'offering richer experiences' and 'the intention to recommend' were analysed within two options: the respondent who chose the website of microfiction or the respondent who chose the other answers: gallery without microfiction or 'I don't know':

a. The variable of 'more interesting presentation' and the variable 'offering richer experiences' are strongly positively

TABLE II.

THE CORRELATION BETWEEN THE VARIABLES [OPTIONS: 'THE WEBSITE WITH MICROFICTION' OR THE OTHER ANSWERS: \{THE WEBSITE WITHOUT MICROFICTION OR 'I DON’T KNOW'\}]

\begin{tabular}{|l|l|}
\hline $\begin{array}{l}\text { 'the most interesting presentation' - 'richer } \\
\text { experience' }\end{array}$ & $\begin{array}{l}\text { Positive, statistically significant, test chi-square } \mathrm{p}<0.05, \mathrm{Fi}=0.60, \mathrm{Tetrachoric} \\
\text { correlations=0.82 }\end{array}$ \\
\hline $\begin{array}{l}\text { 'the most interesting presentation' - } \\
\text { 'recommendation to friend' }\end{array}$ & $\begin{array}{l}\text { Positive, statistically significant } \text { - the chi-squared test } \mathrm{p} .<0.05, \text { and } \mathrm{Fi}=0.62, \\
\text { Tetrachoric correlations }=0.88\end{array}$ \\
\hline $\begin{array}{l}\text { 'the richer experience' - 'recommendation } \\
\text { to friend' }\end{array}$ & $\begin{array}{l}\text { Positive, statistically significant - the chi-squared test } \mathrm{p} .<0.05, \mathrm{Fi}=0.39, \mathrm{Tetrachoric} \\
\text { correlations=0.59 }\end{array}$ \\
\hline $\begin{array}{l}\text { The group which is not interested in art }(1, \\
2, \text { or } 3) \text { and the group which is interested in } \\
\text { art (4-5) }\end{array}$ & $\begin{array}{l}\text { There is no difference between the groups in the dimensions: 'liking virtual galleries', } \\
\text { 'richer experience' or 'recommendation to friend' }\end{array}$ \\
\hline
\end{tabular}


correlated (the chi-squared test $\mathrm{p} .<0.05$, $\mathrm{Fi}=0.60$, Tetrachoric correlations $=0.82$ ).

b. The variable 'more interesting presentation' strongly positively correlates with the variable 'intention to recommend' (the chi-squared test $\mathrm{p} .<0.05$, and $\mathrm{Fi}=0.62$, Tetrachoric correlations $=0.88$ )

c. The variable 'much richer experiences' and the variable 'recommendation' are weakly positively correlated (the chi-squared test $\mathrm{p}<0.05, \quad \mathrm{Fi}=0.39, \quad$ Tetrachoric correlations $=0.59$ )

d. There is no difference between the assessment of the online exhibition with microfiction or without between the group of respondents who liked the artworks (first group: 4 or 5) and those who disliked the artworks (another group - 1,2 or 3 points) (chi-square test, $\mathrm{p}>0.05$ )

e. There is no difference between the assessment of online exhibitions between the group of respondents who are interested (4-5) and those who are not interested in art/visual art (1, 2 or 3$)$.

5. The results with reference to the questions about the website of the National Museum of Warsaw point out that:

a. The majority of respondents $(62 \%)$ agreed with the statement: "the online museum presentation and digitalization of museum objects allow me to look at the museum exhibition in a way which suits me";

b. The majority of respondents (68\%) supported the engagement of museums in creating online galleries;

c. The online museum did not necessary encourage the respondents to visit the traditional museum;

To sum up:

- The hypothesis H1: The online enhanced context with microfiction leads to a more positive attitude of the respondent towards the website in the dimensions of liking the website and offering a 'richer' experience - was confirmed.
- The hypothesis H2: The online enhanced context with microfiction leads to the behavioural intention of viewer: the intention to recommend the website to a friend - was rejected

- The hypothesis H3: The viewer's interest in art is a factor which influences the preference of the virtual gallery by viewer - was rejected

\section{E. Limitations}

The following points underline the limitations of the present study:

1-Although the procedure of the study allows respondents to express their opinion about the preferred format of presentation, the present study is not based on the experiment aiming to make comparisons between the group of respondents who viewed the 'virtual gallery' with standard data and a different group of respondents who viewed the 'virtual gallery with microfiction'.

2- The stimuli: the choice of artworks and the microfictions was arbitrary, and the style and content of presented artworks varied (graphics, pastels, and acrylic). The procedure did not include the respondents' evaluation on what level the artworks and microfictions corresponded within an artistic theme.

3- The results refer to the 'general' website presentation, not to particular artworks. The respondents did not evaluate each artwork and microfiction.

4-Apart from the demographic data, the viewer's characteristics included few other variables.

5-The sample: non-random sample, the sample of respondents was relatively small, and homogenous in age.

\section{DISCUSSION}

The results of this present study should be framed within much broader topics: How to enhance the Internet user's experience during the visit to the website with virtual art exhibition? Does this enhancement of the user's art experience correlate with strengthening the relationship between the Internet user (possible customer) and the museum/gallery brand? Does the virtual gallery influence the brand equity and customer equity for art exhibitions? This scope of research questions should also be formulated and addressed with reference to the groups of sponsors and donors, as these groups play a crucial role in the existence and development of cultural art organizations.

TABLE III.

THE RESPONDENTS’ ATTITUDE TO THE DIGITAL MUSEUMS; STATISTICALLY SIGNIFICANT DIFFERENCE MARKED *

\begin{tabular}{|l|l|l|l|}
\hline & \multicolumn{3}{|c|}{ All respondents N=50 } \\
\cline { 2 - 4 } & \multicolumn{1}{|c|}{$\begin{array}{c}\text { Negative } \\
(\mathbf{1 - 2})\end{array}$} & $\begin{array}{c}\text { Neutral } \\
(\mathbf{3})\end{array}$ & $\begin{array}{c}\text { Positive } \\
(\mathbf{4 - 5})\end{array}$ \\
\hline $\begin{array}{l}\text { In my opinion, the online museum presentation and digitalization of museum } \\
\text { objects allows me to look at the museum exhibition in a way which suits me }\end{array}$ & $12 \% *$ & $26 \%$ & $62 \% *$ \\
\hline The online museum encourages me to visit the traditional museum & $16 \%$ & $36 \%$ & $48 \%$ \\
\hline Museums and galleries should aim to create online exhibitions & $10 \% *$ & $22 \%$ & $68 \% *$ \\
\hline
\end{tabular}


The present study indicates that respondents assessed the virtual gallery with microfictions as the more interesting form of presentation and offering a 'richer' experience compared to the standard presentation. However, the 'enhanced presentation' does not necessarily lead to recommendations of the online gallery to friends. The present study also points out that the respondents had a positive attitude to the process of digitalization of exhibitions by museums, but this positive attitude was not necessarily connected with the intention to visit museum in person. There was no difference between the choices of the preferred online art gallery between the group of respondents who are and who are not interested in art.

As regards to management implications, the present study indicates that the strategy of enhancing the Internet user's art experience may be based on linking together two different artworks: visual art and literature. Considering the amount of digitalized objects in museums' virtual galleries, it would not be possible to create 'the literature' story for each artwork. However, the museum may select a few of the artistic objects, and create the 'enhanced literature presentation' as promotional materials. For individual artists the present study also suggests 'telling the story' about artworks as a tool for enhancing the Internet user's experience. Although, this strategy raises the question - to what extent can the museum modify the context without the artist's agreement, if the context may change the meaning of artwork?

In the broader context of brand equity and customer equity, the results of the present study indicate the link between the enhanced context and both constructs. The 'virtual gallery with microfiction' led to the more positive attitude of the respondents, subsequently creating 'better associations' with artistic brand, therefore enhancing the brand equity (see model of brand equity proposed by Aaker (1996)). Moreover, the brand equity, together with value equity and relationship equity, influences the customer equity on business markets (Rust, Lemon, \& Zeithaml 2001), and this connection may be similar on the online art galleries market. It is worth noting that another aspect tested in the empirical study - the positive referrals - also may be linked to brand equity (due to loyalty) and to the customer equity as:

- the positive referrals create the indirect value of the customer (see - Ryals 2008)

- the positive referrals may indicate customer's loyalty which influences the customer equity (see - Kossecki 2009)

As it was mentioned above, there are still few research papers investigating the fundamental questions about the elements which constitute the brand equity of a virtual art exhibition, and about the drivers of customer equity for the website with a virtual art exhibition. Therefore future research lies in:

- the field of the more extensive study about the connection between the customer equity and brand equity with reference to the websites of art museum/individual artists;
- how other strategies of modifying the context - e.g. implementing music, sound, poems - influence the Internet users' perception of virtual galleries;

- the relation between the purpose of Internet user's visit and the perception of virtual art galleries. In the present study, the respondents focused on evaluating the online presentation due to the 'artistic' merits. The Internet user's experience may be different if they had, for example educational motivations.

- the dynamic changes and interrelations between the art experience and the patron's visit to the virtual gallery. The process of the art experience can change over the time: the first visit may differ from subsequent visits, therefore the scope of the research questions indicated above should take into account the factor of 'time' as an important variable.

\section{REFERENCES}

[1] Aaker D. A. (1996), "Measuring Brand Equity Across Products and Markets", California Management Review. Spring96, Vol. 38, No. 3, 102-120.

[2] Brieber D., Nadal M., Leder H. (2015), "In the white cube: museum context enhances the valuation and memory of art", Acta Psychologica, 154 (2015), 36-42, doi:10.1016/j.actpsy.2014.11.004

[3] Brieber D., Nadal M., Leder H., Rosenberg R. (2014), "Art in Time and Space: Context Modulates the Relation between Art Experience and Viewing Time", PLOS ONE, June 2014, Volume 9, Issue 6, e99019, 18.

[4] Camarero C., Garrido M. J., Vicente E., (2010), “Components of art exhibition brand equity for internal and external visitors", Tourism Management, 31 (2010), 495-504, doi: 10.1016/j.tourman.2009.05.011

[5] Cela-Conde C. J., Agnati L., Huston J. P., Mora F., Nadal M. (2011), "The neural foundations of aesthetic appreciation", Progress in Neurobiology 94(2011) 39-48, doi:10.1016/j.pneurobio.2011.03.003

[6] Corredor J. (2006), "General and domain-specific influence of prior knowledge on setting of goals and content use in museum websites", Computers \& Education, 47 (2006), 207-221, doi: 10.1016/j.compedu.2004.10.010

[7] Cupchik G. C., Vartanian O., Crawley A., Mikulis D. J. (2009), "Viewing artworks: Contributions of cognitive control and perceptual facilitation to aesthetic experience", Brain and Cognition, 70 (2009), 84-91, doi:10.1016/j.bandc.2009.01.003

[8] Gartus A., Leder H. (2014), "The White Cube of the Museum Versus the Gray Cube of the Street: The Role of Context in Aesthetic Evaluation", Psychology of Aesthetics, Creativity, and the Arts, 2014, Vol. 8, No. 3, 311-320, http://dx.doi.org/10.1037/a0036847

[9] Jarrier E., Bourgeon-Renault D. (2012), "Impact of Mediation Devices on the Museum Visit Experience and on Visitors' Behavioural Intentions", International Journal Of Arts Management, Fall 2012, Volume 15, Number 1, 18-29.

[10] Marty P. F. (2011), "My lost museum: User expectations and motivations for creating personal digital collections on museum websites", Library \& Information Science Research, 33 (2011), 211219, doi:10.1016/j.lisr.2010.11.003

[11] Kirk U., Skov M., Hulme O., Christensen M. S., Zeki S. (2009), "Modulation of aesthetic value by semantic context: An fMRI study", NeuroImage, $\quad 44$ (2009), 1125-1132, doi:10.1016/j.neuroimage.2008.10.009

[12] Kossecki P. (2009), Valuation and Value Creation of Internet Companies - Social Network Services (September 26, 2009). Available at $\quad$ SSRN: http://ssrn.com/abstract $=1478713 \quad$ or http://dx.doi.org/10.2139/ssrn.1478713

[13] Leder H., Carbon C.-C., Ripsas A.-L. (2006), "Entitling art: Influence of title information on understanding and appreciation of paintings", $\begin{array}{llll}\text { Acta Psychologica, } 121 & \text { (2006), }\end{array}$ doi:10.1016/j.actpsy.2005.08.005

[14] Leder H., Nadal M. (2014), "Ten years of a model of aesthetic appreciation and aesthetic judgments: The aesthetic episode Developments an challenges in empirical aesthetics", British Journal of Psychology, 2014, 105, 443-464, doi:10.1111/bjop.12084 
[15] Nelles W. (2012), "Microfiction: What Makes a Very Short Story Very Short?", NARRATIVE, Vol 20, No. 1, January 2012, 87-104.

[16] Pallas J., Economides A. A. (2008). "Evaluation of art museums' web sites worldwide", Information Services \& Use, 28 (2008), 45-57. doi:10.3233/ISU-2008-0554

[17] Pavlidis G., Koutsoudis A., Arnaoutoglou F., Tsioukas V., Chamzas C. (2007), "Methods for 3D digitization of Cultural Heritage", Journal of Cultural Heritage, January 2007, 8 (2007), 93-98, doi:10.1016/j.culher.2006.10.007

[18] Pelowski M., Akiba F. (2011), "A model of art perception, evaluation and emotion in transformative aesthetic experience", New Ideas in Psychology, 29 (2011), 80-97, doi:10.1016/j.newideapsych.2010. 04.001
[19] Rust R. T., Lemon K. N., Zeithaml V. A. (2001), "Where Should the Next Marketing Dollar Go?", Marketing Management, 10(3), 24-28.

[20] Ryals L. (2008), "Determining the indirect value of a customer", Journal of Marketing Management, 24(7/8), 847-864.

[21] Skov M., Ingwersen P. (2014), "Museum Web search behavior of special interest visitors", Library \& Information Science Research, 36 (2014), 91-98, http://dx.doi.org/10.1016/j.lisr.2013.11.004

[22] Swami V. (2013), "Context Matters: Investigating the Impact of Contextual Information on Aesthetic Appreciation of Paintings by Max Ernst and Pablo Picasso", Psychology of Aesthetics, Creativity, and the Arts, 2013, Vol. 7, No. 3., 285-295, doi: 10.1037/a0030965

[23] Sylaiou S., Mania K., Karoulis A., White, M. (2010), "Exploring the relationship between presence and enjoyment in a virtual museum", International Journal of Human-Computer Studies, 68 (2010), 243253. doi:10.1016/j.ijhes.2009.11.002 